\title{
Spotted Lanternfly Lycorma delicatula (White) (Hemiptera: Fulgoridae) ${ }^{1}$
}

Taryn B. Griffith and Jennifer L. Gillett-Kaufman²

\section{Introduction}

Originating from northern China, the spotted lanternfly, Lycorma delicatula (White), is a serious pest due to their high reproductive capacity and large host range. Spotted lanternfly is the approved ESA common name, however these insects are also referred to as the spot clothing wax cicada, or the spotted wax cicada (Figure 1). The spotted lanternfly is not native to the Americas, although it has become established in Pennsylvania (Hao et al. 2016). The first report of the pest was in 2014 in Berks County, PA (Barringer et al. 2015), and an additional report was made in 2018 in Frederick County, VA (Day 2018), as well as Delaware (Murillo 2018). It is unknown how far this infestation is able to spread.

\section{Distribution}

The native range of Lycorma delicatula includes China, India, and Vietnam. It was first reported outside these countries in South Korea in 1932 and has since become abundant there. Scientists have modeled potential distributions in different regions including Australia, America, and Europe. These models help regulatory agencies determine the potential distribution of this insect and establish plans to prevent the pest from spreading into areas where it could thrive (Jung et al. 2017). In the United States., it has currently (July 2018) been found in Delaware, New Jersey, New York, Pennsylvania, and Virginia, but its wide host range makes it likely to establish a wider distribution.

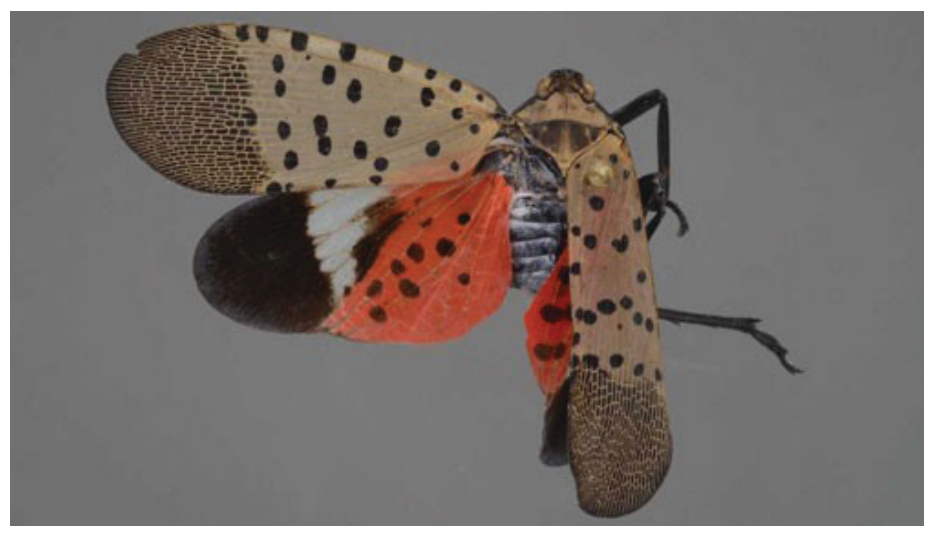

Figure 1. Adult Lycorma delicatula (White).

Credits: Lyle J. Buss, UF/IFAS

\section{Description and Life Cycle Eggs}

During the fall, Lycorma delicatula lay their eggs in an ootheca, or egg casing, which is covered by a brownish gray waxy secretion (Figure 2). The species is univoltine; however, females lay multiple masses of eggs once per year. The spotted lanternfly overwinters in the egg stage on surfaces like trees with smooth bark, specifically Ailanthus altissima (tree of heaven; an introduced tree in the US, native to China), (Dara et al. 2015, Han et al. 2008) or even buildings (Zhai et al. 2014). Although the spotted lanternfly prefers stable and smooth surfaces, any surface with at least approximately $2.5 \mathrm{~cm}$ of relatively smooth area will suffice (L. Donovall, personal observation).

1. This document is EENY-714, one of a series of the Entomology and Nematology Department, UF/IFAS Extension. Original publication date August 2018. Revised October 2019. Visit the EDIS website at https://edis.ifas.ufl.edu for the currently supported version of this publication.

2. Taryn B. Griffith; and Jennifer L. Gillett-Kaufman, associate Extension scientist, Entomology and Nematology Department; UF/IFAS Extension, Gainesville, FL 32611.

The Institute of Food and Agricultural Sciences (IFAS) is an Equal Opportunity Institution authorized to provide research, educational information and other services

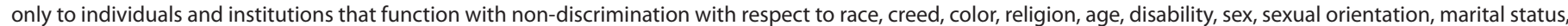

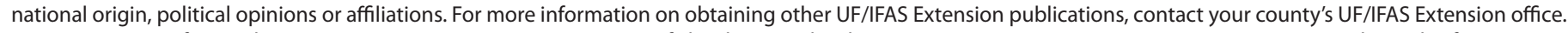
U.S. Department of Agriculture, UF/IFAS Extension Service, University of Florida, IFAS, Florida A \& M University Cooperative Extension Program, and Boards of County Commissioners Cooperating. Nick T. Place, dean for UF/IFAS Extension. 


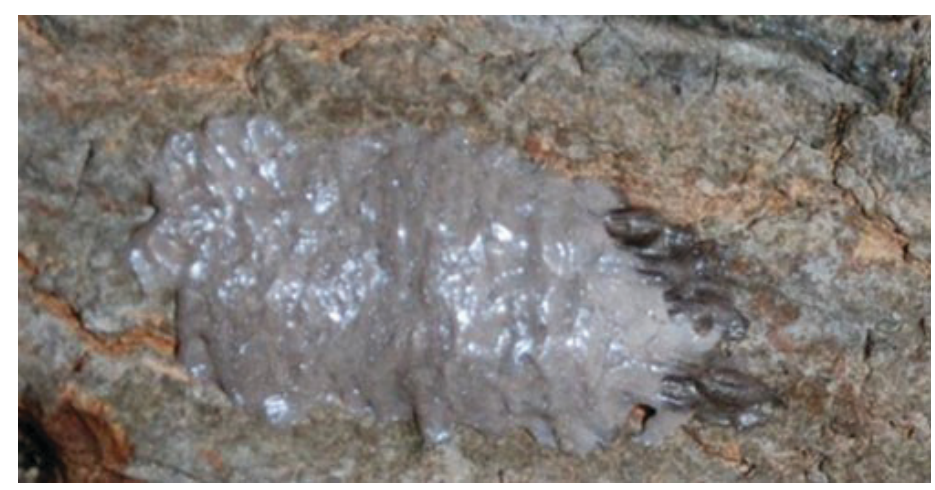

Figure 2. Egg mass of Lycorma delicatula (White).

Credits: L. Barringer, Pennsylvania Department of Agriculture

The majority of eggs are laid on the lower portions of the tree (Tomisawa et al. 2013); however, eggs were observed 1 to $3 \mathrm{~m}$ up the tree and are laid as far up as $13 \mathrm{~m}$ on Prunus with rough lower bark (Kim et al. 2011). Eggs have also been observed at a height of as low as $1 \mathrm{~cm}$ (L. Donovall and M. Park, personal observation), but laying eggs at breast-height on woody trees with a diameter larger than $15 \mathrm{~cm}$ was most frequently observed. In Korea, an average of 3.4 egg masses were laid on each tree; however, the concentrations can be dramatically higher in Pennsylvania, with up to 197 egg masses per tree (Lee et al. 2014).

\section{Nymphs}

All four instars (nymphal growth stages) are mostly black, but the fourth and final instar has a different marking pattern. The first three instars have white spots and the fourth instar has red markings on the body (Figure 3). Early instars are easily knocked off trees by wind (Choi et al. 2012), but they fall less frequently as they develop (Kim et al. 2011). Nymphs aggregate on the host plant to feed, preferring woody stems as they grow older and progressing onto tree trunks and branches as they develop into the fourth instar. When the density of nymphs on a host plant is high, it is more likely that aggressive behavior between nymphs will occur as they compete for the best feeding locations. During these encounters, the residing nymph will raise its forelimbs at the approaching nymph, which will either leave or attempt to mount the residing nymph. If the residing nymph is mounted, it attempts to throw the intruder off. In this scenario, it is most likely for the original nymph to maintain control over its feeding space rather than the new nymph taking control (Choi et al. 2011).

In Korea, eggs hatch in May, with nymphs ascending up the host plant after emerging in the early morning from the operculum, an oblong opening at the end of the ootheca (Han et al. 2008; Anderson et al. 2016). Large groups of nymphs feeding on the same host will cause the affected area to wilt and eventually die (Han et al. 2008).
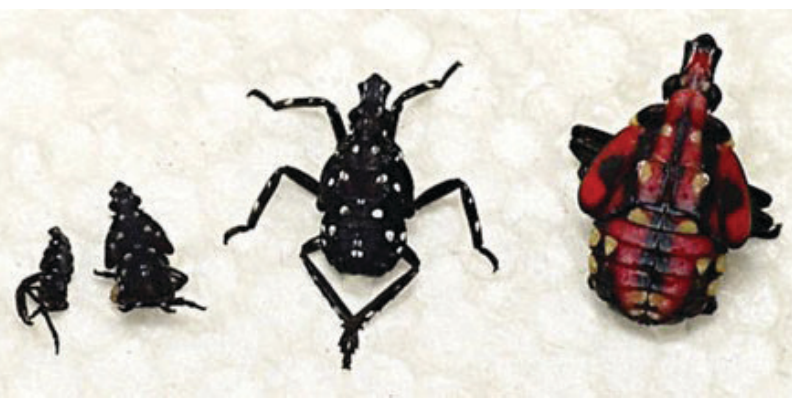

Figure 3. Four instars of Lycorma delicatula (White).

Credits: Tea-Kesting-Handly, Pennsylvania Department of Agriculture

\section{Adults}

Adult Lycorma delicatula have light brown forewings dotted with black spots, and the base color darkens along the tips of the wing. The cryptic coloration allows for Lycorma delicatula to blend against the branches of the host plant (Figure 4) (Frantsevich et al. 2008). The hindwings are brightly colored, red with black spots. They also have a white band separating the red from the black tips of their hindwings. Females are slightly larger than males, having a body length of 20 to $25 \mathrm{~mm}$ versus 17 to $20 \mathrm{~mm}$ (Barringer et al. 2015). Another account measures females at 22 to 27 $\mathrm{mm}$ and males at 21 to $22 \mathrm{~mm}$ from head to tip of the wings (Dara et al. 2015). Females have longer legs as well, ranging from 18 to $22 \mathrm{~mm}$ while the male leg length is between 15 and $18 \mathrm{~mm}$ (Barringer et al. 2015).

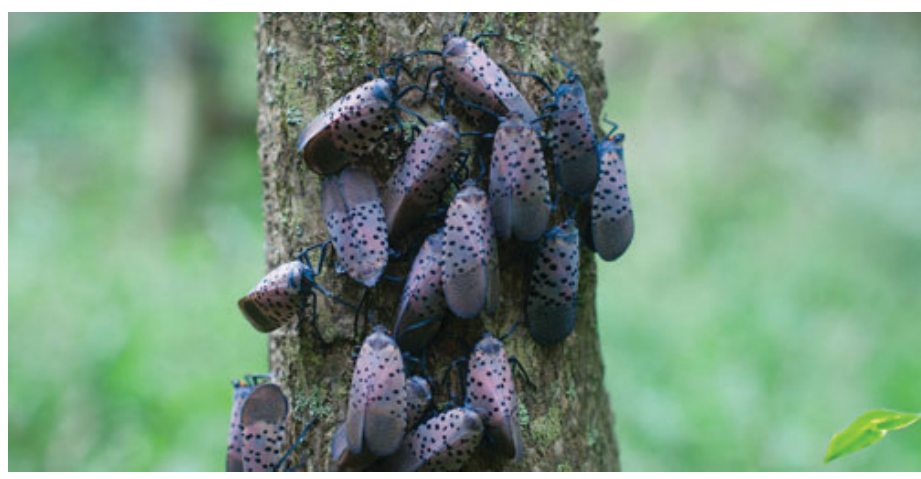

Figure 4. Cluster of spotted lanternfly, Lycorma delicatula (White). Credits: Hillary Peterson, Penn State Fruit Research and Extension Center

The spotted lanternfly has piercing-sucking mouthparts that are adapted to feeding from plant stems. The mouthparts are located under the front portion of the head capsule and consist of a cone shaped and a tubular labrum (upper lip). There is a deep longitudinal groove along the dorsal surface containing the stylet fascicle (cylindrical mouthpart used to pierce the surface of the plant to feed). Like all other hemipterans, the stylet fascicle is comprised of four parts, two mandibular and two maxillary stylets. The size of the mouthparts correlates to body size (Hao et al. 2016). 
The adults of Lycorma delicatula rely largely on camouflage and the coloration of their wings to defend against predators. The bright red warning coloration of the hindwings is used to ward off predators. When disturbed, Lycorma delicatula flashes its wings open to reveal the bright, contrasting colors of the hindwings, to startle potential predators and warn them that the insect is chemically defended. Adults use cytotoxins as chemical defenses to deter predators (Barringer and Smyers 2016). These are acquired through feeding from host plants, mainly the tree of heaven, Ailanthus altissima (Barringer and Smyers 2016).

Lycorma delicatula is reported to be a weak flier, rarely flying over $3.3 \mathrm{~m}$ (Chou 1946); however, it has been noted that a spotted lanternfly dispersal behavior is to fly up into wind that can transport them over $10 \mathrm{~m}$, this behavior is repeated to travel even greater distances (Barringer, personal communication). In addition, Lycorma delicatula can hop 1 to $1.3 \mathrm{~m}$ (Chou 1946) to escape predation if a predator is unperturbed by their coloration (Frantsevich et al. 2008). After emergence, adults begin to disperse. First appearing in July, the adult Lycorma delicatula becomes more abundant in August. Adults begin to lay eggs in September, then begin to die off by November after one or two hard frosts. The insect overwinters as egg masses (Dara et al. 2015; Anderson et al. 2016).

\section{Host Plants}

Lycorma delicatula is found on over 70 known host plants, with 25 identified in Pennsylvania, ranging from apples, grapes, birch, cherry, lilac, maple, poplar, stone fruits, and the tree of heaven (Barringer et al. 2016; Dara et al. 2015). Lycorma delicatula primarily feeds on Ailanthus altissima, greatly preferring it over many other species, and is likely to establish itself where Ailanthus altissima is present (Anderson et al. 2016). Lycorma delicatula and the tree of heaven are both equally invasive species originating from the same native regions of China and other parts of Asia. Using their haustellate (sucking) mouthparts, typical of the order Hemiptera, they feed on the sap in the phloem (Ding et al. 2006). Their host range includes economically important plants, particularly Vitis vinifera (common grape vine), which makes them an unsuitable biological control agent for the tree of heaven (Ding et al. 2006).

\section{Damage}

Nymphs and adults of the spotted lanternfly feed on the sap of a host plant through the phloem of young leaves and stems, affecting photosynthesis and potentially causing the plant to experience stunted growth and/or mortality (Ding et al. 2006; Anderson et al. 2016). In addition, the spotted lanternfly excretes a sugary excrement known as honeydew. Honeydew buildup promotes the growth of fungal sooty mold by providing a rich substrate for mold growth. Sooty mold grows in black mats, interrupting the host plants ability to photosynthesize by blocking sunlight from the surfaces of the leaves.

\section{Management}

North American management efforts focus on early detection to prevent the spread of the spotted lanternfly to new locations. Eggs can be removed by hand by scraping egg masses off trees. Sticky traps can also be made by wrapping paper around the trees and coating them with adhesive (Anderson 2015). Due to their high level of mobility and the possibility of the insecticide affecting a beneficial insect, it is difficult to determine a location on the tree to use insecticides for management, making the most effective insecticides systemic (absorbed by the tree and affects the insect when they feed) or spraying the tree entirely (Anderson 2015). Alternatively, both the adults and nymphs are equally repelled by lavender oil, but adults are more adversely affected by linalool oil than nymphs (Yoon et al. 2011).

In China, a native parasitic wasp, Anastatus orientalis (Hymenoptera: Euplemidae), is reported to have attacked up to $69 \%$ of eggs; however, it currently is not considered as a biological control in North America because it is not native and the potential effects of introduction have yet to be evaluated (Choi et al. 2014). Chinese native insect predators include Dryinus browni (Yan et al. 2008) and Dryinus lycormae (Dong 1983; Dong 1987; Yang 1994). Ooencyrtus kuvanae, an egg parasitoid of Lycorma delicatula is under investigation by researchers to the University of Delaware (Lui and Mottern 2017).

Predation of the spotted lanternfly was first observed in 2015 by a wheel bug, Arilus cristatus (Hemiptera: Reduviidae) (Barringer et al. 2016). The wheel bug, a type of assassin bug, is a common generalist predator of insects, including forest pests, and is widely distributed through the US. The second observation was of the predatory stink bug, Apoecilus cynicus (Hemiptera: Pentatomidae), feeding on the underside of a spotted lanternfly. Both the nymphs and adults of the spotted lanternfly and the stink bug are found commonly on maple trees. Both accounts of predation were observed in Berks County, PA (Barringer et al. 2016). 


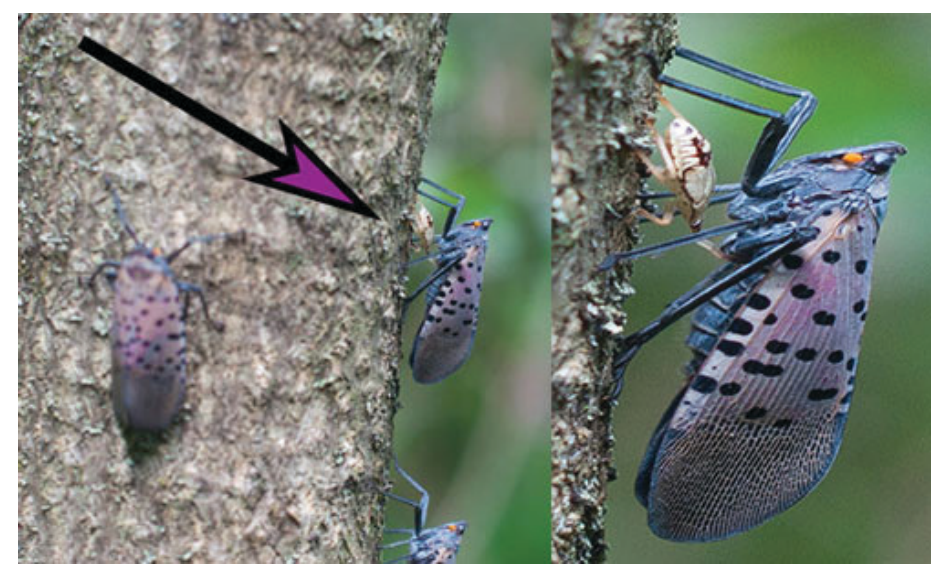

Figure 5. A nymph of the predatory stink bug Podisus serieventris feeds on an adult spotted lanternfly Lycorma delicatula (White), in Kempton, Pennsylvania

Credits: Hillary Peterson, Penn State Fruit Research and Extension Center

\section{Acknowledgements}

Special thanks to Christian Fowkes and family for collecting specimens of Lycorma delicatula we used for photographs in this publication and for inclusion in the University of Florida insect teaching collection.

\section{Selected References}

Anderson H, Baufeld P, Bourgoin T, Donovall L, Montecchio L, Park M, Sanchez Pena G, Wang X, Chouibani M, Petter F, Grousset F. 2015. "Pest risk analysis for Lycorma delicatula (Hemiptera: Fulgoridae)." European and Mediterranean Plant Protection Organization 16-21777.

Barringer E, Donovall L, Spichiger S, Lynch D, Henry D. 2015. "The first New World record of Lycorma delicatula (Insecta: Hemiptera: Fulgoridae)." Entomological News 125: 20-23.

Barringer E, Smyers E. 2016. "Predation of the spotted lanternfly, Lycorma delicatula (White) (Hemiptera: Fulgoridae) by two native Hemiptera." Entomological News 126: 71-73.

Choi M, Yang Z, Wang X, Tang Y, Hou Z, Kim J, Byeon Y. 2014. "Parasitism rate of egg parasitoid Anastatus orientalis (Hymenoptera: Eupelmidae) on Lycorma delicatula (Hemiptera: Fulgoridae) in China." Korean Journal of Applied Entomology 53: 135-139.

Choi D, Kim K, Jang K. 2011. "Agonistic interactions between nymphs of Lycorma delicatula (Hemiptera: Fulgoridae)." Journal of Asia-Pacific Entomology 14: 21-25.
Dara SK, Barringer L, Arthurs SP. 2015. “Lycorma delicatula (Hemiptera: Fulgoridae): A new invasive pest in the United States." Journal of Integrated Pest Management 6: $1-6$.

Day E. 2018. Spotted Lanternfly in Virginia. Virginia Cooperative Extension. Accessed 2/5/2018. https://ext.vt.edu/ agriculture/commercial-horticulture/spotted-lanternfly. html

Ding J, Wu Y, Zheng H, Fu W, Reardon R, Liu M. 2006.

"Assessing potential biological control of the invasive plant, tree-of-heaven, Ailanthus altissima." Biocontrol and Technology 16: 547-566.

Dong JF. 1983. "Studies on the biology of Dryinus sp., a hymenopterous parasitoid of Lycorma delicatula White (Homopt: Fulgoridae)." Natural Enemies of Insects 5: 228-230.

Dong JF. 1987. "Rearing method of Dryinus lycormae Yang." Henan Science \& Technology 1: 17-18.

Frantsevich L, Ji A, Dai Z, Wang J, Fransevich L, Gorb SN. 2008. "Adhesive properties of the arolium of a lanternfly, Lycorma delicatula (Auchenorrhyncha, Fulgoridae)." Journal of Insect Physiology 54: 818-827.

Hao Y, Dietrich CH, Dai W. 2016. "Structure and sensilla of the mouthparts of the spotted lanternfly Lycorma delicatula (Hemiptera: Fulgoromorpha: Fulgoridae), a polyphagous invasive planthopper." PLOS ONE. 11. https:// doi.org/10.1371/journal.pone.0156640

Han JM, Kim H, Lim EJ, Lee S, Kwon Y, Cho S. 2008. "Lycorma delicatula (Hemiptera: Auchenorrhyncha: Fulgoridae: Aphaeninae) finally, but suddenly arrived in Korea." Entomological Research 38: 281-286.

Jung J, Jung S, Byeon D, Lee W. 2017. "Model-based prediction of potential distribution of the invasive insect pest, spotted lanternfly Lycorma delicatula (Hemiptera: Fulgoridae), by using CLIMEX." Journal of Asia Pacific Biodiversity 30: 532-538.

Kim JG, Lee EH, Seo YM, Kim NY. 2011. "Cyclic behavior of Lycorma delicatula (Insecta: Hemiptera: Fulgoridae) on host plants." Journal of Insect Behavior 24: 423-435.

Lee J, Moon S, Ahn H, Cho S, Yang J, Yoon C, Kim G. 2009. "Feeding behavior of Lycorma delicatula (Hemiptera: Fulgoridae) and response on feeding stimulants of some plants." Korean Journal of Applied Entomology 48: 467-477. 
Lee YS, Jang MJ, Kim JY, Kim JR. 2014. “The effect of winter temperature on the survival of lantern fly, Lycorma delicatula (Hemiptera: Fulgoridae) eggs." Korean Journal of Applied Entomology 53: 311-315.

Liu H, Mottern J. 2017. "An old remedy for a new problem? Identification of Ooencyrtus kuvanae (Hymenoptera: Encyrtidae), an egg parasitoid of Lycorma delicatula (Hemiptera: Fulgoridae) in North America." Journal of Insect Science 17: 1-6. https://doi.org/10.1093/jisesa/iew114

Murillo. 2018. New invasive species in Va. threatens grapes and hops crops. Washington's Top News. Accessed 2/13/2018. https://wtop.com/virginia/2018/02/ new-invasive-species-va-threaten-grape-hops-crops/?utm content=buffera $4585 \& u t m \_$medium $=$social\&utm_ source $=$ facebook.com\&utm_campaign=buffer

Park J, Kim M, Lee S, Shin S, Kim J, Park I. 2009. "Biological characteristics of Lycorma delicatula and the control effects of some insecticides." Korean Journal of Applied Entomology 48: 53-57.

Tomisawa A, Ohmiya S, Fukutomi H, Hayashi K, Ishikawa T. 2013. "Biological notes on Lycorma delicatula (White) (Hemiptera, Fulgoridae) in Ishikawa Prefecture, Japan." Japanese Journal of Entomology 16: 3-14.

Yoon C, Moon S, Jeong J, Shin Y, Cho S, Ahn K, Yang J, Kim G. 2011. "Repellency of lavender oil and linalool against spot clothing wax cicada, Lycorma delicatula (Hemiptera: Fulgoridae) and their electrophysiological responses." Journal of Asia-Pacific Entomology 14: 411-416.

Zhai YL, Gao JS, Yan LL, Zhang JL. 2014. "Occurrence of Homoptera insects in Prunus armeniaca species, and control methods." Entomological Research in Centre China 10: $223-227$. 